Journal of Animal and Veterinary Advances 9 (12): 1765-1770, 2010

ISSN: $1680-5593$

(C) Medwell Journals, 2010

\title{
Biological Characteristics of Rat Spermatogonial Stem Cells Cultured on Sertoli Cell Feeder Layer in vitro
}

\author{
${ }^{1}$ Deying Zhang, ${ }^{1}$ Guanghui Wei, ${ }^{1}$ Dawei He, ${ }^{2}$ Jing Zhu, ${ }^{1}$ Xing Liu and ${ }^{1}$ Tao Lin \\ ${ }^{1}$ Department of Urology, ${ }^{2}$ Institute of Pediatric Research, \\ Children's Hospital of Chongqing Medical University, 400014 Chongqing, China
}

\begin{abstract}
Spermatogonial Stem Cells (SSCs) are the unique stem cells in the body that can transmit genetic information to the offspring, which are recently demonstrated to be with more perspectives in cell engineering. In this study, an easy and feasible method of rat SSCs in vitro culture system is established which can facilitate the study on SSCs and the biological characteristics of rat SSCs cultured in vitro were observed. Sertoli cells and SSCs were separated by two-step enzyme digestion from 0-1 and 6-7 days old Sprague-Dawley rats, respectively. SSCs were inoculated on the Sertoli cells on the 5th day when the feeder layer formed. Morphology of coculture cells was observed and expression of SSCs markers Vasa, SMAD1, Stella, Dazl and GCNF, HSP90 $\alpha$, Oct- 4 , integrin- $\beta 1$ were detected by RT-PCR and Western blot respectively. SSCs began to proliferate and differentiate $24 \mathrm{~h}$ after being cultured on the Sertoli cells layer and there were a few A-paired (Apr) spermatogonia cell colonies. With time prolongation, the number of Apr cell colonies decreased gradually, meanwhile the number of aligned (Aal) cell colonies increased, then Aal cell colonies retained stable quantity after $120 \mathrm{~h}$ in culture, it could retain $(54.1 \pm 6.2$ days $)$ under the condition the culture medium being changed every 4-5 days. We concluded that rat SSCs can proliferate colonially on the feeder layer of Sertoli cells and retain stable morphous and quantity. The SSCs culture system fed by Sertoli cells layer can serve as a tool to faciliate SSCs and SSCs-Sertoli cells interaction research.
\end{abstract}

Key words: Spermatogonial stem cell, sertoli cell, culture, spermatogenesis, gamete biology, rat

\section{INTRODUCTION}

Spermatogonial Stem Cells (SSCs) are the foundation for spermatogenesis in which they transmit genetic information to the next generation by producing sperms. The spermatogenesis after birth is firstly the self-renewal proliferation and differentiation of SSCs while it is rather difficult to investigate the biology of SSCs in vivo, because of the complexity of testicular structure and function and interactions among testes, cerebral ganglion and pituitary gland (Feng et al., 2002). Elucidation of regulatory mechanisms of SSCs would be facilitated by in vitro studies that provide a defined microenvironment reconstituted ex vivo. Meanwhile, the study of selfrenewal and differentiation of SSCs will be greatly facilitated by in vitro culture of enriched biologically active cell populations. Sertoli cells, the only somatic cells within seminiferous tubules interacting directly with germ cells of all stages, provide SSCs a favorable microenvironment for spermatogenesis in vivo through physical support and expression of surface proteins and soluble factors which nourish germ cells (Griswold, 1995; Hess et al., 2006; Shinohara et al., 2003). The close association with SSCs suggests that the Sertoli cells play a key role in maintaining the undifferentiated and pluripotent state of these spermatogenic cells while simultaneously supporting germ cell differentiation and spermatogenesis (Mauduit et al., 1999; Ohta et al., 2000; Ryu et al., 2006). Although, there are various methods to isolate SSCs of high purity from testes which take only $<2 \%$ of germ cells, including Percoll density gradient centrifugation, Fluorescence Aactivated Cell Sorting (FACS) and Magnetic Cell Sorting (MACS), they are difficult and expensive (Hofmann et al., 2005; Ryu et al., 2004). In the present study, an in vitro coculture system of SSCs on Sertoli cells feeder layer was established which provides a good model to investigate the biological behavior of SSCs more directly and more concordant with in vivo conditions and will be more useful to study the targets and mechanisms of environmental toxins or drugs interferences effects on SSCs as well.

\section{MATERIALS AND METHODS}

Experimental animals: Male Sprague Dawley (SD) rats of 0-1 and 6-7 days old were obtained from Experimental Animal Center, Chongqing Medical University, Chongqing, China. The Animal Ethical Committees of the

Corresponding Author: Guanghui Wei, No.136, Zhongshan 2 RD, Yuzhong District, Chongqing, 400014, China 
Institute of Zoology approved the use of animals for the studies reported herein and Chongqing Medical University approved the experiments.

Isolation and culture of sertoli cells: Sertoli cells were isolated from 0-1 days old rats following the method described by Grima J (Grima et al., 1998) with some modifications. Briefly, 10 testes obtained from $0-1$ day old rats on ice sterily were washed in $4^{\circ} \mathrm{C}$ PBS solution, albuginea and visible blood vessel were dissected; testicular tissue was cut into fragments $<1 \mathrm{~mm}^{3}$, exposed to $0.25 \%$ (w:v) trypase for $15 \mathrm{~min}$ at $37^{\circ} \mathrm{C}$. The trypase (GibcoBRL) was then quenched by addition of DMEM/F12 (1:1, v:v; GibcoBRL) with 10\% FBS (Hyclone) when seminiferous tubules monitored under inverted microscopy were spread. Centrifugated at $800 \mathrm{r} \mathrm{min}^{-1}$ for $5 \mathrm{~min}$ to remove interstitial cells and trypase in supernatant, then the remains were exposed to $0.1 \%(\mathrm{w}: \mathrm{v})$ collagenase IV (Sigma) for $10-15 \mathrm{~min}$ at $37^{\circ} \mathrm{C}$. Suspension was filtered by 200 -eyes- cell-cribble. Cell viability was measured by Trypan Blue Staining. The cells were adjusted to $0.5 \times 10^{5} \mathrm{~mL}^{-1}, 5 \mathrm{~mL}$ of them were aliquoted into each $25 \mathrm{~cm}^{2}$ culture flask which was then placed in $34^{\circ} \mathrm{C}$ incubation room with $5 \% \mathrm{CO}_{2}$ and $95 \%$ humidity. After 3-4 h, medium was blotted when Sertoli cells adhered and polarized, then DMEM/F12 medium was added. The cells were cultured for $36-48 \mathrm{~h}$ at $34^{\circ} \mathrm{C}$, treated with $20 \mathrm{mmol} \mathrm{L}^{-1}$ Tris-Cl (Sigma) for $2.5 \mathrm{~min}$ to remove residual germ cells, then continued to culture with DMEM/F12 medium.

Isolation and culture of SSCs: Two-step enzyme digestion method (Kanatsu-Shinohara et al., 2003) was used with some modifications. 20 testes obtained from 6-7 days old rats on ice were washed in $4^{\circ} \mathrm{C}$ PBS solution, albuginea and visible blood vessel were dissected, testicular tissue was cut into fragments of $<1 \mathrm{~mm}^{3}$ approximately, exposed to $1 \mathrm{mg} \mathrm{mL}^{-1}$ collagenase IV for $15 \mathrm{~min}$ at $37^{\circ} \mathrm{C}$, centrifugated at $800 \mathrm{r} \mathrm{min}^{-1}$ for $5 \mathrm{~min}$ to remove interstitial cells and collagenase, then exposed to $0.25 \%(\mathrm{w}: \mathrm{v})$ trypase and $0.1 \%(\mathrm{w}: \mathrm{v})$ alidase (Sigma) for $10 \mathrm{~min}$ at $37^{\circ} \mathrm{C}$, quenched by DMEM/F12 with $10 \% \mathrm{FBS}$.

The solution was filtered with 400 -eyes-cell-cribble, centrifugated at $1000 \mathrm{r} \mathrm{min}^{-1}$ for $5 \mathrm{~min}$, washed twice with PBS. Single cell suspension of $4 \times 10^{5}$ cells $\mathrm{mL}^{-1}$ approximately was prepared with DMEM/F1 2 hol-medium with $10 \% \mathrm{FBS}, 1 \mathrm{mmol} \mathrm{L}{ }^{-1}$ sodium pyruvate, non-essential amino acid, minimum essential vitamin, $0.1 \mathrm{mmol} \mathrm{L}^{-1} \beta$ mercaptoethanol (invitrogen) and $0.5 \mathrm{mmol} \mathrm{L}^{-1} \mathrm{~L}$ LIF (Sigma). About $5 \mathrm{~mL}$ of the suspension was inoculated into each $25 \mathrm{~cm}^{2}$ flask, cultured for $3 \mathrm{~h}$ at $34^{\circ} \mathrm{C}$. Draw-off the medium gently when somatic cells adhered and polarized. The un-adhered cells were re-inoculated into a
$25 \mathrm{~cm}^{2}$ flask $3 \mathrm{~h}$ later, the medium were draw off to re-inoculate and culture for $12 \mathrm{~h}$. When most living cells adhered the medium was piped out and the left cells were purified SSCs. SSCs were cultured with DMEM/F12 hol-medium.

Coculture of SSCs on sertoli cell feeder layer: On the 5 th day, prior to the inoculation of SSCs, the $80-90 \%$ confluenced Sertoli cells feeder layer were treated with mitomycin C (10 $\mathrm{g} \mathrm{mL}^{-1}$ in DMEM/F12; Sigma) for $3 \mathrm{~h}$ to restrict further proliferation. Then the cocultured cells were added with DMEM/F12 hol-medium and cultured at $34^{\circ} \mathrm{C}$. The culture medium was changed every 4-5 days. Growth status of SSCs cell colonies were observed under inverted phase-contrast microscope at different time point, cell colonies of different cell type in 10 fields of vision of each flask were counted randomly. Sloshed the flask slightly so as to uniform distribute the exfoliated cells and counted those exfoliated cells.

Immunocy tochemistry: Vimentin(as the marker of Sertoli cell) and germ cell nuclear factor (GCNF), HSP90 $\alpha$, Oct-4, integrin- $\beta 1$ (as the marker of SSCs) were detected, respectively by immunocytochemistry. Sertoli cells and SSCs were inoculated respectively on the coverslip in 6-well plate and taken out when single cells layer formed; fixed with $4 \%$ paraformaldehyde for $10-15 \mathrm{~min}$; the fixed cells was washed by $\mathrm{PBS}\left(0.01 \mathrm{~mol} \mathrm{~L}^{-1}, \mathrm{pH} 7.5\right)$, incubated by $3 \% \mathrm{H}_{2} \mathrm{O}_{2}$ for $5 \mathrm{~min}$, to eliminate activity of endogenous peroxydase; the samples were incubated with $10 \%$ goat serum for $10 \mathrm{~min}$; primary antibody was added: vimentin (1:200, Santa Cruz) and GCNF (1:300, abcam), HSP90 $\alpha$ (1:200, Santa Cruz), Oct-4 (1:200, Santa Cruz), integrin- $\beta 1$ (1:200, abcam), incubated overnight at $4^{\circ} \mathrm{C}$; washed by PBS, added 2nd antibody: biotin labeled goat anti rabbit IgG (1:200, Santa Cruz), incubated for $30 \mathrm{~min}$ at Room Temperature (RT); dropwised SABC, incubated for $30 \mathrm{~min}$ at $37^{\circ} \mathrm{C}$; coloration with $\mathrm{DAB}$, stained nuclear slightly with hematoxylin, dehydrated and transparence, mounted with neutral gum. Stained brown was taken as positive. The ratio of the positive cells among 100 cells wascounted in at least 5 high-fold microscopic fields randomly.

RT-PCR: The total RNA was extracted from purified SSCs using a RNApure total RNA isolation kit (Bioteke), according to the manufacturer's instructions. First-strand cDNA was obtained from $5 \mu \mathrm{L}$ of total RNA using AMV First Strand cDNA Synthesis Kit (KeyGEN). Amplification reactions were performed in $25 \mu \mathrm{L}$ of PCR mixtures containing $5 \mu \mathrm{L} 5 \times$ PrimeSTAR ${ }^{\mathrm{TM}}$ buffer $\left(\mathrm{Mg}^{2+}\right.$ plus $), 2 \mu \mathrm{L}$ dNTPs mixture (2.5 mM each), $0.25 \mu \mathrm{L}$ PrimeSTAR ${ }^{\mathrm{TM}} \mathrm{HS}$ 


\begin{tabular}{|c|c|c|}
\hline $\begin{array}{l}\text { Target } \\
\text { gene }\end{array}$ & Sequence of primers & $\begin{array}{l}\text { Product } \\
\text { size (bp) }\end{array}$ \\
\hline \multirow[t]{2}{*}{ Vasa } & F: 5'-GCGAGACTACATCTACAAC-3' & \\
\hline & R: 5'-GAGTATCTTCACAGTCATTA-3' & 135 \\
\hline \multirow[t]{2}{*}{ SMAD1 } & F: 5'-CTCATGTCATTTATTGCCG-3' & \\
\hline & R: 5'-CTCGCTTATAGTGGTAGGGA-3' & 138 \\
\hline \multirow[t]{2}{*}{ Stella } & F: 5'-CTATCATCGTCGTCAAAGG-3' & \\
\hline & R: 5'-CTCTGCTCAATCCGAACAA-3' & 177 \\
\hline \multirow[t]{2}{*}{ Dazl } & F: 5'-CCCAAGGAAGGCTGGAAAGG-3' & \\
\hline & R: 5'-GCCTGGTCCACTGATTGTTCG-3' & 218 \\
\hline \multirow[t]{2}{*}{$\beta$-actin } & F: 5'-GCTCGTCGTCGACAACGGCTC-3' & \\
\hline & R: 5'-CAAACATGATCTGGGTCATCTTCTC-3' & 353 \\
\hline
\end{tabular}

DNA polymerase $\left(2.5 \mathrm{U}_{\mu} \mathrm{L}^{-1}\right)$ (Takara), $0.5 \mu \mathrm{L}$ first-strand cDNA, $0.5 \mu \mathrm{L}(20 \mathrm{pmol})$ each of the specific primers for Vasa, SMAD1, Stella, Dazl, $\beta$-actin (as reference) (primer sequence) (Table 1) and 16.25 $\mu \mathrm{L}$ RNase free water. Samples were denatured at $94^{\circ} \mathrm{C}$ for $3 \mathrm{~min}$ and sequential 35 cycles at $94^{\circ} \mathrm{C}$ for $30 \mathrm{sec}, 45,50,56,58$ and $56^{\circ} \mathrm{C}$ (Vasa, SMAD1, Stella, Dazl and $\beta$-actin, respectively) for $15 \mathrm{sec}$ and $72^{\circ} \mathrm{C}$ for $30 \mathrm{sec}$ were followed for amplification in a thermal cycler (Eppendorf). After the last cycle, the samples were incubated for an additional $10 \mathrm{~min}$ at $72^{\circ} \mathrm{C}$. The PCR products were separated in a $2 \%$ agarose gel and visualized with UV by staining with $0.05 \%$ ethidium bromide in Tris-acetate EDTA.

SDS-PAGE and western blot: Proteins were extracted from purified SSCs, Sertoli cells using RIPA buffer (PBS, 1\% NP 40, 0.5\% sodium deoxycholate, $0.1 \%$ SDS) (Sangon) including $1 \mathrm{mM}$ phenylmethylsulfonylfluoride (PMSF), testicular tissue of 7 days old rats was used as positive control. About $20 \mu \mathrm{L}$ of each protein samples were separated on a $12 \%$ SDS-polyacrylamide gel (Invitrogen) and blotted onto a Polyvinylidene Fluoride (PVDF) membrane (Bio-Rad). Protein binding sites were blocked for 1-2 $\mathrm{h}$ in blocking buffer: TBST (Tris-buffered saline with Tween-20: $10 \mathrm{mM}$ Tris- $\mathrm{HCl}, \mathrm{pH} 7.5,150 \mathrm{mM} \mathrm{NaCl}$, $0.05 \%$ Tween-20) containing 5\% nonfat dry milk at RT. Primary antibodies were diluted in blocking buffer and incubated overnight at $4^{\circ} \mathrm{C}$ : GCNF $(1: 600)$, HSP90 $\alpha$, integrin- $\beta 1$, Oct-4 (1:300), $\beta$-actin (1:3000). Membranes were washed 3 times with TPBT for $10 \mathrm{~min}$. After incubation with secondary antibodies: goatanti-rabbitHRP or rabbit-anti-mouse-HRP (1:5000, Santa Cruz) in blocking buffer for $1 \mathrm{~h}$ at RT, membranes were washed 3 times in TBST for $10 \mathrm{~min}$. Protein bands were detected using the enhanced chemiluminescence detection method (ECL, KeyGEN).

Statistic analysis method: Experiments were repeated at least three times. Data of SSCs colonies and exfoliated cells in results were expressed in means \pm SEM and analyzed by One-Way analysis of variance (ANOVA), using SPSS 10.0 program (SPSS Inc., USA). A value of $\mathrm{p}<0.05$ was chosen as an indication of statistical significance.

\section{RESULTS}

Harvest Rate and Purity of Sertoli Cells and SSCs: About $(2-4) \times 10^{7}$ Sertoli cells could be harvested from 10 rats of $0-1$ day old averagely with $92-95 \%$ living cells, the single cell suspension was purified by differential adherence, about $5-6 \%$ relic germ cells were eliminated by $20 \mathrm{mmol} \mathrm{L}^{-1}$ Tris-Cl. Purity of Sertoli cell identified by vimentin was $96-98 \%$ (Fig. 1a). (2-5) $\times 10^{6}$ SSCs could be harvested from 20 rats of 6-7days old, with 90-93\% living cells; SSCs were purified by differential adherence with the identification by immunohistochemistry of GCNF, HSP90 $\alpha$, Oct-4, integrin- $\beta 1$ (Fig. 1b-e), more than 95\% germ cells isolated from 6-7 days old SD rats were SSCs.

Formation of sertoli cell feeder layer in vitro: Sertoli cells adhered and polarized at 3-4 h after inoculation, took about $85 \%$ of the total amount of cells. Suspended cells were germ cells pre-adherence. The slenderness spindle cells with no branches were fibroblast. All Sertoli cells adhered after $7-8 \mathrm{~h}$, culture and proliferated rapidly at period of 12-14 $\mathrm{h}$ with little phagotrophic granulo-body being observed in cytoplasm. At $48 \mathrm{~h}$, Sertoli cell body enlarged, spread on the flask well to form single cell layer. With time of culture went on, almost all round cells disappeared, Sertoli cells took more than $90 \%$ of all culture cells with small mount of fibroblast among them (Fig. 1a). At $120 \mathrm{~h}$, cell proliferation slowed down, while Sertoli cell body still enlarged, the cytoplasm spread dramatically with 3-4 enations like irregular polygon, 80-90\% cells conjugated and formed the single cell layer.

Proliferation of sscs on sertoli cells layer: The living SSCs adhered to feeder layer of Sertoli cells at 6-7 h of inoculation. Cellular proliferation and differentiation of SSCs were observed to be double-cells morphous $24 \mathrm{~h}$ later (Fig. 2a). At 48 h, aligned cell colonies of no more than 8 cells connected by intercellular bridges, and typical 4-cell colonies were observed (Fig. 2b). At $72 \mathrm{~h}$, more aligned cell colonies of more than 8 cells were observed (Fig. 2c). At $120 \mathrm{~h}$ and $240 \mathrm{~h}$, local aligned cells fused and accumulated and maintained at a relative stable amount (Fig. 2d). Exfoliated cells in the culture solution were the highest amount at $24 \mathrm{~h}$ and then decreased and maintained at a stable level (Fig. 3). Under the condition of changing medium every 4-5 days, the average time of cell colonies maintaining stable was $54.1 \pm 6.2$ days, the longest time was 75 days.

Gene and protein expression of sscs and sertoli cell markers in isolated cells: The expression of germ-line stem cell specific genes and proteins: Vasa, SMAD1, 


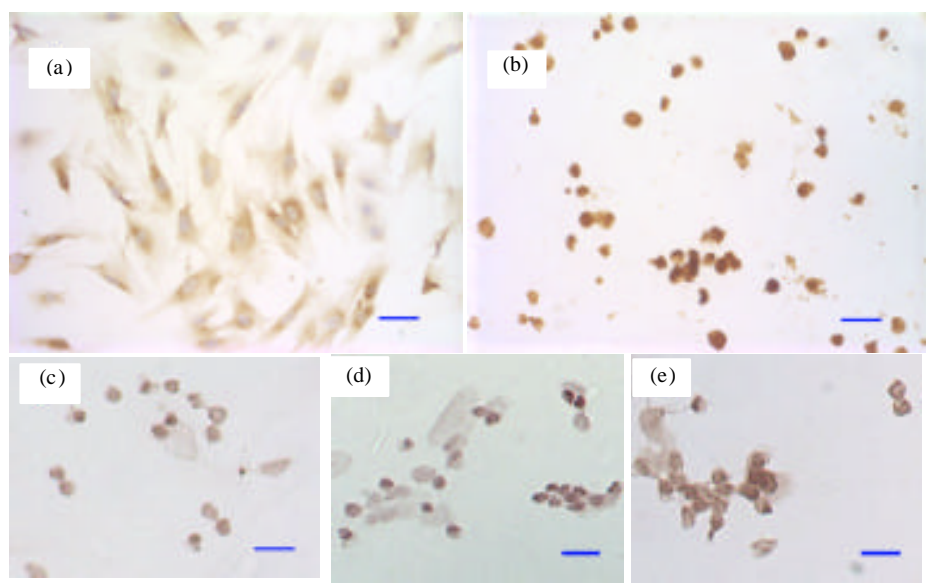

Fig. 1: Identification of Sertoli Cells and SSCs by immunohistochemistry stain. (a) expression of vimentin in Sertoli cells; (b) expression of GCNF in SSCs; (c) expression of HSP90 $\alpha$ in SSCs; (d) expression of Oct-4 in SSCs; (e) expression of integrin-âl in SSCs. Bars represent $50 \mu \mathrm{m}$

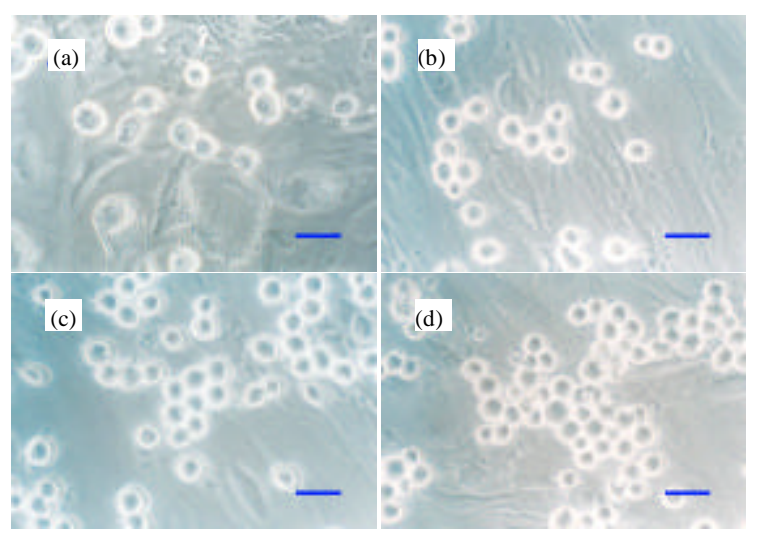

Fig. 2: Cell colonies of spermatogonial stem cells on Sertoli cell monolayer. (a) Symmetry and dissymmetry Apar colonies at $24 \mathrm{~h}$; (b) Aal colonies composed by 4-cells with inter-cell bridge at $48 \mathrm{~h}$; (c) Aal colonies composed by more than 8 cells at $72 \mathrm{~h}$; (d) Stable Aal colonies after $120 \mathrm{~h}$. Bars represent $50 \mu \mathrm{m}$

Stella, Dazl and GCNF, HSP90 $\alpha$, Oct-4, integrin- $\beta 1$ in purified SSCs were detected by RT-PCR and Western blot respectively. As shown in Fig. 4 and 5, Vasa, SMAD1, Stella, Dazl and GCNF, HSP90 $\alpha$, Oct- 4 , integrin- $\beta 1$ were expressed in purified SSCs, of which Vasa, Stella, Dazl, GCNF, integrin- $\beta 1$ were expressed at a high level as expected. Furthermore, Vimentin expression was detected in purified Sertoli cells and absent in purified SSCs while SSCs marker GCNF and Oct-4 were detected in Sertoli cells with a very low concentration.

The single A-type (As) spermato-gonia are generally considered to contain the SSCs population in rodents which functions to continually renew developing germ cells in the seminiferous epithelium and demonstrated to be of more perspectives in cell

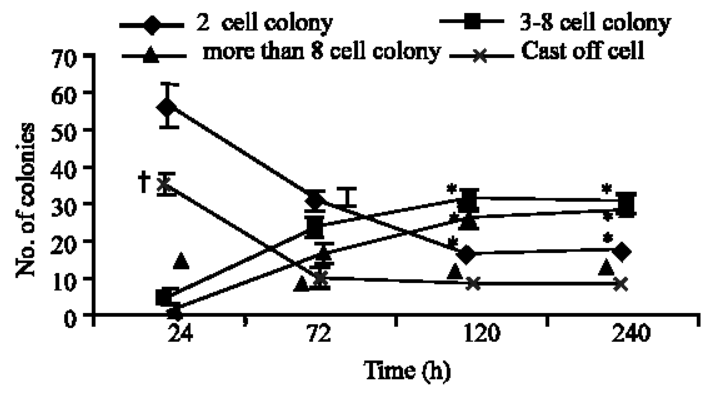

Fig. 3: Number of SSCs colonies at different time and cast-off cells (number/hp, $\mathrm{n}=5, \mathrm{x} \pm s$ ). *: compared between cultured SSCs colony number of the same morphous in $120 \mathrm{hr}$ and $240 \mathrm{~h}$, ANOVA ttest, $\mathrm{p}>0.05 . \Delta$ : compared among number of cast-off cells in medium at different time point, ANOVA, t-test, $p>0.05$. Compared between $†$ and $\Delta$, t-test, $\mathrm{p}<0.01$

engineering as well (Brinster, 2002; Meachem et al., 2001). In this experiment Sertoli cells was isolated from germ cells by differential speed adherence for the reason that Sertoli cells adhere faster than germ cells and most germ cells mixed in Sertoli cells were removed after treatment with 20 mmol L ${ }^{-1}$ Tris hypoosmotic solution. SSCs marker GCNF and Oct-4 slightly expression in Sertoli cells indicates small number of SSCs residual which has no effect on this coculture system. Since germ cells of 6-7 days old rats are SSCs exclusively in vitro cultured germ cells isolated from testes of 6-7 days rats by differential speed adherence were SSCs uniquely. With cell identification by the marker of vimentin and GCNF, integrin- $\beta 1$, HSP $90 \alpha$, Oct- 4 , the purity of Sertoli cells and SSCs were $96-98 \%$ and $>95 \%$, respectively. The purified SSCs expressed Vasa, Stella, 


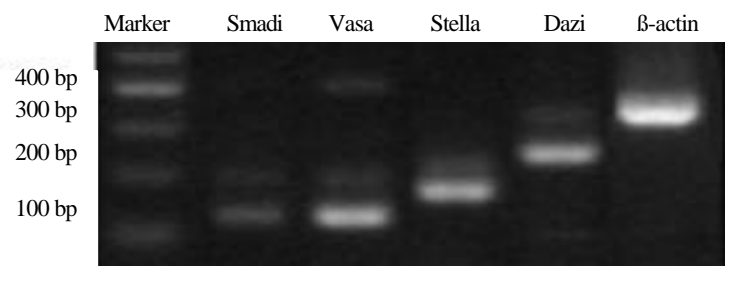

Fig. 4: RT-PCR of purified SSCs population for Vasa, SMAD1, Stella and Dazl, that expressed specifically in germ-line stem cells. Vasa, Stella and Dazl are expressed with a high concentration

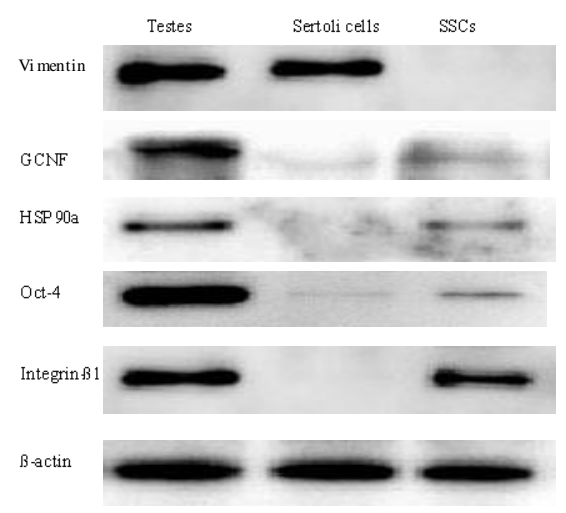

Fig. 5: Western Blot of cultured cells for proteins expressed specifically in SSCs and Sertoli cells. Vimentin was detected in Sertoli cells and absent in SSCs. SSCs markers GCNF, HSP90 $\alpha$, Oct-4 and integrin- $\beta 1$ are expressed in SSCs with a high concentration; meanwhile, GCNF and Oct- 4 are detected in Sertoli cells with a very low concentration

Dazl, GCNF, integrin- $\beta 1$ with high concentration. Based on the above results, it is simple and reliable to isolate and purify Sertoli cells and SSCs by differential speed adherence. One of Sertoli cells function in vitro is feeding SSCs. Sertoli cells not only support SSCs but also secrete immune protective factors, growth factors and nutrition factors such as IGF1-1, bFGF, TGF, EGF, IL-1, IL-6, TNF, IFN- $\alpha, \mathrm{LIF}, \mathrm{SCF}, \mathrm{GDNF}$ and transferrin, etc, provide a favorable microenvironment for SSCs proliferation and differentiation as in vivo (Huleihel and Lunenfeld, 2004; Parks et al., 2003). In addition, cell-cell conjunction and adhesion facilitates intercellular communication between Sertoli cells and SSCs (Jegou, 1993). On the one hand this will induce Sertoli cells secreting growth factors and nutrition factors necessary to proliferation and differentiation of SSCs, on the other hand, cellular products of SSCs can prolong the living time and sustain normal function of Sertoli cells which favor long time survival and proliferation of SSCs in vitro.
Thus in this experiment, primary Sertoli cells of neonatal rats were chosen as feeder cells. Although, several Sertoli cell lines were established to support SSCs culture (Merhi et al., 2001; Pognan et al., 1997) the insufficiency of these cell lines was that upon the longterm culture or isolation procedures for the establishment of cell lines, the cells become transformed and lose some of their typical characteristics, making them unsuitable for feed SSCs or support spermatogenesis (Kurita and Sakai, 2004). In this experiment, inoculated round or ovalis SSCs were observed to adhere to the surface of Sertoli cells firstly, then proliferate and form colonies on Sertoli cells layer. Cells were connected by intercellular bridges, favored intercellular transmission of external signals among the connected cells rapidly, so as to the keep in step to divide and proliferate (Dettin et al., 2003).

About $120 \mathrm{~h}$ later, the number and morphous of cell colonies maintained at a stable status. Moreover, number of cast-off cells in culture solution kept stable at different time point except for an obvious increase at $24 \mathrm{~h}$. It probably because that a number of SSCs adhering to Sertoli cells propotionally within $24 \mathrm{~h}$ inoculation, the non-adherent or dead SSCs were exfoliated in the culture solution; after they were removed by changing with medium at $24 \mathrm{~h}$, the number of cast-off cells maintained stable.

It also indicated that SSCs in stable connection grew well. Under condition of changing medium every 4-5 days in this experiment, the average time spermatogonial colonies maintained stable was (54.1 \pm 6.2 ) days.

Although, there were in vitro models of Sertoli cells and germ cells coculture (Grima et al., 1998; Lee and Cheng, 2005; Van Pelt et al., 2002), most of them were spermatogonia or downstream germ cells inoculated to Sertoli cells with few observation on developmental morphous of SSCs in vitro. In this experiment, Sertoli cells served as feeder layer to culture SSCs which different from mixed coculture of Sertoli cells with germ cells. The biological behaviors of single SSCs in vitro could be observed more directly and mechanism during the complex process of spermatogenesis could be studied as well. While attentions should be paid to the amount of Sertoli cells inoculated and time of SSCs inoculation. If there is too much Sertoli cells inoculated, it is hard to form single cell layer because of the accumulation and deformity of Sertoli cells which eventually affect the formation and observation of SSCs colonies. If SSCs are inoculated before the formation of single Sertoli cell layer, SSCs will be set among Sertoli cells which is the same as mixed culture. In this experiment, $(2-3) \times 10^{5}$ Sertoli cells were inoculated into $25 \mathrm{~cm}^{2}$ culture flask, single cell layer formed after 4-5 days culture, then SSCs were inoculated 
at the ratio of $1: 1$. The SSCs culture system fed by Sertoli cells layer makes it possible for SSCs to maintain in vitro for a long time.

\section{CONCLUSION}

Rat SSCs can proliferate colonially on the feeder layer of Sertoli cells, retain stable morphous and quantity. The SSCs culture system fed by Sertoli cells layer can serve as a tool to faciliate SSCs and SSCs-Sertoli cells interaction research.

\section{ACKNOWLEDGEMENTS}

This research was supported by a grant from the National Natural Science Foundation of China (No. 30672196). We thank Dr. Ya-Sha Li, Dr. Guan-Xin Liu and Dr. Xiao-Ping Zhang for excellent technical assistance.

\section{REFERENCES}

Brinster, R.L., 2002. Germline stem cell transplantation and transgenesis. Science, 296: 2174-2176.

Dettin, L., N. Ravindranath, M.C. Hofmann and M. Dym, 2003. Morphological characterization of the spermatogonial subtypes in the neonatal mouse testis. Biol. Reprod., 69: 1565-1571.

Feng, L.X., Y. Chen, L. Dettin, R.A.R. Pera and J.C. Herr et al, 2002. Generation and in vitro differentiation of a spermatogonial cell line. Science, 297: 392-395.

Grima, J., C.C.S. Wong, L.J. Zhu, S.D. Zong and C.Y. Cheng, 1998. Testin secreted by Sertoli cells is associated with the cell surface, and its expression correlates with the disruption of Sertoli-germ cell junctions but not the inter-Sertoli tight junction. $\mathrm{J}$. Biol. Chem., 273: 21040-21053.

Griswold, M.D., 1995. Interactions between germ cells and Sertoli cells in the testis. Biol. Reprod., 52: 211-216.

Hess, R.A., P.S. Cooke, M.C. Hofmann and K.M. Murphy, 2006. Mechanistic insights into the regulation of the spermatogonial stem cell niche. Cell Cycle, 5: 1164-1170.

Hofmann, M.C., L. Braydich-Stolle, L. Dettin, E. Johnson and M. Dym, 2005. Immortalization of mouse germ line stem cells. Stem Cells, 23: 200-210.

Huleihel, M. and E. Lunenfeld, 2004. Regulation of spermatogenesis by paracrine/autocrine testicular factors. Asian J. Androl., 6: 259-268.

Jegou, B., 1993. The Sertoli-germ cell communication network in mammals. Int. Rev. Cytol., 147: 25-96.
Kanatsu-Shinohara, M., N. Ogonuki, K. Inoue, H. Miki, A. Ogura, S. Toyokuni and T. Shinohara, 2003. Longterm proliferation in culture and germline transmission of mouse male germline stem cells. Biol. Reprod., 69: 612-616.

Kurita, K. and N. Sakai, 2004. Functionally distinctive testicular cell lines of zebrafish to support male germ cell development. Mol. Reprod. Dev., 67: 430-438.

Lee, N.P. and C.Y. Cheng, 2005. Protein kinases and adherens junction dynamics in the seminiferous epithelium of the rat testis. J. Cell Physiol., 202: 344-360.

Mauduit, C., S. Hamamah and M. Benahmed, 1999. Stem cell factor/c-kit system in spermatogenesis. Hum. Reprod. Update, 5: 535-545.

Meachem, S., V. von Schonfeldt and S. Schlatt, 2001. Spermatogonia: Stem cells with a great perspective. Reproduction, 121: 825-834.

Merhi, R.A., L. Guillaud, C. Delouis and C. Cotinot, 2001. Establishment and characterization of immortalized ovine Sertoli cell lines. In vitro Cell Dev. Biol. Anim., 37: 581-588.

Ohta, H., K. Yomogida, K. Dohmae and Y. Nishimune, 2000. Regulation of proliferation and differentiation in spermatogonial stem cells: The role of c-kit and its ligand SCF. Development, 127: 2125-2131.

Parks, J.E., D.R. Lee, S. Huang and M.T. Kaproth, 2003. Prospects for spermatogenesis in vitro. Theriogenology, 59: 73-86.

Pognan, F., M.T. Masson, F. Lagelle and C. Charuel, 1997. Establishment of a rat Sertoli cell line that displays the morphological and some of the functional characteristics of the native cell. Cell Biol. Toxicol., 13: 453-463.

Ryu, B.Y., K.E. Orwig, H. Kubota, M.R. Avarbock and R.L. Brinster, 2004. Phenotypic and functional characteristics of spermatogonial stem cells in rats. Dev. Biol., 274: 158-170.

Ryu, B.Y., K.E. Orwig, J.M. Oatley, M.R. Avarbock and R.L. Brinster, 2006. Effects of aging and niche microenvironment on spermatogonial stem cell self-renewal. Stem Cells, 24: 1505-1511.

Shinohara, T., K.E. Orwig, M.R. Avarbock and R.L. Brinster, 2003. Restoration of spermatogenesis in infertile mice by Sertoli cell transplantation. Biol. Reprod., 68: 1064-1071.

Van Pelt, A.M.M., H.L. Roepers-Gajadien, I.S. Gademan, L.B. Creemers, D.G. De Rooij and F.M.F. van DisselEmiliani, 2002. Establishment of cell lines with rat spermatogonial stem cell characteristics. Endocrinology, 143: 1845-1850. 